\title{
A padaria antropofágica de Ednardo: uma análise de discurso da canção Artigo $26^{1}$
}

Cláudia Rejanne Pinheiro Grangeiro"

Raul Azevedo de Andrade Ferreira ${ }^{\text {*w }}$

\section{Resumo}

Este trabalho propõe-se a uma análise dos efeitos de sentido produzidos pelo contato da língua portuguesa com a língua francesa na letra da canção Artigo 26, do compositor cearense Ednardo. Para a análise, mobilizamos o arcabouço teórico-metodológico da chamada análise do discurso francesa, de autores como Michel Pêcheux (1995), Michel Foucault $(1992,1997,1999)$ e Courtine (1981), demonstrando os mecanismos pelos quais o texto promove o diálogo entre a cultura brasileira e a herança da França revolucionária republicana, ressignificando os elementos de uma e de outra cultura, por meio do pastiche, e fazendo emergir um discurso antropofágico que se constitui com base em três regiões do dizer distintas: a Revolução Francesa, o discurso literário da Padaria Espiritual e o discurso da cultura popular brasileira.

Palavras-chave: Análise do discurso. Ednardo. Artigo 26.

\section{"Das dunas brancas onde eu queria ficar": o Ceará falando para o mundo}

José Ednardo Soares Costa Sousa iniciou sua carreira musical em Fortaleza, Ceará, na década de 1970. Cantor e compositor de projeção internacional, suas músicas são executadas em vários países da América Latina, Europa e Estados Unidos da América. São mais de quatrocentas músicas e letras, distribu-

Doutora em Linguística e Língua Portuguesa pela Faculdade de Ciências e Letras da Universidade Estadual Paulista Julio de Mesquita Filho, com estágio no Centre d'Étude des Discours, Images, Textes Écrits, Communication, Sorbonne Nouvelle Paris XII. Professora do Departamento de Línguas e Literaturas da Universidade Regional do Cariri. E-mail: claudiarejannep@yahoo. com.br

** Doutor em Teoria da Literatura pela Universidade Federal de Pernambuco. Professor do Departamento de Línguas e Literatura da Universidade Regional do Cariri. E-mail: raulandradef@hotmail.com

Data de submissão: mar. 2016 - Data de aceite: maio 2016 http://dx.doi.org/10.5335/rdes.v12i1.5869 
ídas em quinze discos originais, dezesseis discos de compilações, duas trilhas musicais para teatro, dois especiais para TV e quatro trilhas musicais de cinema. ${ }^{2}$ Em 1979, em plena ditadura militar, foi protagonista do movimento Massafeira Livre, que reuniu vários artistas cearenses das mais diversas linguagens, inclusive o poeta Patativa do Assaré, no Teatro José de Alencar. No ano seguinte foi gravado o disco Massafeira, um clássico da discografia brasileira. Dentre os seus maiores sucessos constam o Pavão Mysteriozo, música tema da novela Saramandaia (cantada por grupos de maracatu e por nações indígenas brasileiras), Terral, Ingazeiras, Lagoa de Aluá, Longarinas, Enquanto engoma a calça, Flora, A manga rosa, Beiramar, Carneiro, Artigo 26, dentre outras produções. Suas músicas são interpretadas por vários cantores da MPB, como Elba Ramalho, Fagner, Belchior, Ney Matogrosso, Vânia Abreu, Amelinha, Nonato Luiz, dentre muitos outros.

Em 2015, lançou em Fortaleza o DVD 40 anos de Canção, edição comemorativa dos quarenta anos de aniversário do álbum Meu corpo minha embalagem todo gasto na viagem - Pessoal do Ceará (1975). O compositor mescla canções extremamente líricas com elementos do pastoril, do maracatu, do frevo, da literatura de cordel com rock e outros ritmos. Como descreve o pesquisador Gilmar de Carvalho: "[...] Ele cria em cima do que seria raiz, sem folclorizar seu trabalho. É um artesão da canção, um compositor cearense/brasileiro/universal" (2013, p. 2).

Neste trabalho, procedemos a uma análise dos efeitos de sentido produzidos pelo contato da língua portuguesa com a língua francesa na letra da canção Artigo 26, gravada no disco Berro (1976), no intuito de demonstrar o papel do "discurso outro" ou discurso "do outro", que, ao estabelecer relações interdiscursivas com o discurso de partida, constituem uma posição de sujeito a partir da qual novos sentidos são produzidos.

\section{Alguns conceitos-chave da análise do discurso francesa}

O que chamamos de análise do discurso francesa é um conjunto de trabalhos e estudos constituídos em torno dos escritos que Michel Pêcheux produziu a partir dos anos 1960 na França. São importantes também os postulados do multifacetado e inquietante filósofo Michel Foucault, com o qual Pêcheux travará, em período posterior, diálogos e duelos (GREGOLIN, 2004) quase nunca tranquilos. De acordo com essa perspectiva teórica, mobilizamos alguns conceitos-chave para o desenvolvimento das análises, tais como discurso, formação discursiva, sujeito e interdiscurso.

A formulação do conceito de formação discursiva em Foucault está desenvolvida principalmente na obra Arqueologia do saber (1997). Suas investigações sobre o discurso, no entanto, começam em um 
livro anterior, As palavras e as coisas (1999), quando o autor analisa a mudança dos saberes da época clássica para a época moderna. Por meio da análise de determinados domínios de objetos, como a vida, o trabalho e a linguagem, Foucault aponta relações indissolúveis entre o dizer e o fazer.

Distanciando-se da concepção idealista que entende que a linguagem é transparente em relação aos seus referentes, Foucault defende a tese de que a palavra não trabalha como mera representação de objetos cuja realidade encontra-se determinada aprioristicamente em uma essência, mas como instituidora das coisas mediante práticas discursivas. É mediante o "falar sobre" que os referentes são constituídos. Assim sendo, sua análise não procede partindo-se do sujeito ou do objeto, pois, para ele, esses elementos não possuem existência a priori. A existência dos sujeitos e dos objetos apenas se dá a partir do momento em que forem constituídos por práticas sociais. Exemplo disso pode ser verificado pela análise do objeto corpo. Na Idade Média, devido à influência dos discursos religiosos, o corpo do homem não tinha a mesma condição de existência que se percebe a partir do século VIII. Com a criação da ideia de patologia pelo discurso clínico no século VIII, o corpo passa a ser visto como um conjunto de órgãos articulados, como um organismo. As práticas e dizeres do discurso da medicina, portanto, produziram uma nova forma de entendimento, um novo objeto, para esse objeto que é referido quando se utiliza a palavra corpo.

Esses diferentes saberes nasceram, pois, de práticas sociais e discursivas, de formas de organização de enunciados sobre os objetos que constituem a realidade. A reflexão que será desenvolvida em Arqueologia do saber visa dar conta dos princípios que fundamentariam as análises que Foucault desenvolveu em seu livro anterior. Segundo Gregolin (2004, p. 27), Arqueologia do saber é um livro de caráter teórico-metodológico em que o autor reflete sobre seus trabalhos anteriores e sistematiza uma série de conceitos basilares para a abordagem do discurso e suas condições de aparecimento. Assim, para a construção do conceito de formação discursiva, Foucault vai operar construindo os conceitos pela negativa, tendo sempre em vista seu objetivo de descrever os mecanismos de constituição das "ciências do homem". Interessava-lhe, pois, saber o que são esses domínios de objetos, essas massas enigmáticas que chamamos a Medicina, a Gramática, a Economia, a Política, etc.

É, pois, da colocação de tais questões de onde vem o conceito de formação discursiva de Foucault (1997). Para ele, os discursos são uma dispersão, ou seja, são formados por elementos que não estão ligados por nenhum princípio de unidade $a$ priori, cabendo à análise do discurso descrever essa dispersão, buscando as "regras de formação" que regem a formação dos discursos. Assim, para o autor, 
[...] sempre que se puder descrever, entre um certo número de enunciados, semelhante sistema de dispersão e se puder definir uma regularidade (uma ordem, correlações, posições, funcionamentos, transformações) entre os objetos, os tipos de enunciação, os conceitos, as escolhas temáticas, teremos uma formação discursiva (FOUCAULT, 1997, p. 43).

Em Foucault, as regras que determinam uma formação discursiva apresentam-se, pois, como um sistema de relações entre objetos, enunciados, conceitos e estratégias. Todos esses elementos caracterizam a formação discursiva em sua singularidade, possibilitando a passagem da dispersão para a regularidade.

\section{Sujeito e identidade em Foucault e Pêcheux}

$\mathrm{Na}$ esteira da questão da formação discursiva em Foucault está a relação dessa com o sujeito. Embora tenha discorrido em toda a sua obra sobre a problemática dos poderes/saberes na sociedade, sua preocupação não era propriamente com o poder. O objetivo central dos seus estudos foi produzir uma história dos diferentes modos de subjetivação do ser humano em nossa cultura. Assim, sua abordagem em torno dessa questão está diretamente relacionada com a sua crítica às chamadas "analíticas da finitude", quais sejam: a fenomenologia, o positivismo e o marxismo, que se propuseram a definir o homem por meio da análise de seu corpo, da história da produção ou das suas re- lações empíricas como responsáveis pelo que ele é em sua essência.

Para Foucault, a perspectiva dessas analíticas da finitude acabou por cair em um "sono antropológico", ou seja, o sujeito é constituído, mas a filosofia, até o século XIX, quis apresentá-lo como constituinte, como um cogito de tipo cartesiano, um sujeito agenciador, senhor dos seus atos. Contrariamente, para ele, o sujeito foi sendo constituído por longos, árduos e conflituosos acontecimentos discursivos, epistêmicos e práticos. Assim, como seu propósito era construir uma história do presente, ele constrói uma arquegenealogia do sujeito, analisando três modos de objetivação a partir de certas práticas: a) práticas objetivadoras, que permitem pensar um sujeito normalizável como objeto da ciência; b) práticas discursivas, que cumprem o papel de fundadoras epistêmicas; c) práticas subjetivadoras, por meio das quais o sujeito pode pensar-se enquanto tal, tais como a prática da confissão, da psicanálise etc.

Assim, para Foucault, o sujeito não existe $a$ priori, nem sua origem, nem sua suposta essência imanentista. Não há, pois, nenhum tipo de essência identitária per si. A identidade do sujeito é uma construção histórica, temporal, datada e, como tal, fadada ao desaparecimento. O sujeito é disperso, descontínuo; é uma função neutra, vazia, podendo adquirir diversas posições. Segundo o pensador francês, "somos seres de linguagem e não 
seres que possuem linguagem" (FOUCAULT, 1997, p. 20-21).

Nesse sentido, quando Pêcheux traz para a análise do discurso a noção de formação discursiva, ele faz as readaptações relacionando tal conceito à questão da ideologia e da luta de classes. Tratava-se, segundo o próprio Pêcheux, de extrair da noção de Foucault o que "ela tinha de materialista e revolucionária" (PÊCHEUX, 1990, p. 56), justamente a concepção foucaultiana de discurso como prática. Em Pêcheux, a formação discursiva é definida como:

Aquilo que, numa conjuntura dada, determinada pelo estado de luta de classes, determina o que pode e deve ser dito (articulado sob a forma de uma arenga, de um sermão, de um panfleto, de uma exposição, de um programa etc.) (1995, p. 160).

Nesse momento de sua teoria do discurso, Pêcheux rediscute a noção de ideologia, abrindo espaço para a questão das fronteiras maleáveis da formação discursiva (FD) e apontando para sua heterogeneidade. Isso quer dizer que a FD é uma unidade dividida, que, embora seja passível de descrição por suas regras de formação, por suas regularidades, ela não é una, mas heterogênea, heterogeneidade que não é acidental, mas constitutiva de sua regularidade. Assim, no interior de uma mesma FD coabitam vozes dissonantes que se cruzam, entrecruzam, dialogam, opõem-se, aproximam-se, divergem, existindo, dessa forma, espaço para a divergência, para as diferenças, pois uma FD é "constitutivamente frequentada por seu outro" (PÊCHEUX,
1995, p. 57), fazendo com que, de outro modo, o sujeito de uma formação discursiva seja também disperso, heterogêneo e não "totalmente assujeitado" pela sua ideologia, sendo afetado pelo real da língua e pelo real da história. Assim, conforme afirma Gregolin:

Quando adotamos o ponto de vista da Análise do Discurso, focalizamos os acontecimentos discursivos a partir do pressuposto de que [...] o sentido é criado pela relação entre sujeitos históricos e, por isso, a interpretação nasce da relação do homem com a língua e com a história (2004, p. 11).

Sendo, pois, a produção dos sentidos resultante de um conjunto de processos socio-históricos, eles não são transparentes. Os discursos bem como os sujeitos envolvidos em sua produção e circulação são dispersos, esquivos. O sujeito que enuncia o faz de um lugar social, socio-histórico, funcionado como porta-voz desses discursos. Daí deriva a ilusão de univocidade do sujeito e das formações discursivas. No entanto, essa univocidade é desfeita no momento em que se procede a uma análise mais apurada dos processos ideológicos e discursos envolvidos na produção dos sentidos e das subjetividades. As formações discursivas não são homogêneas. Elas são traspassadas, entrecortadas por saberes/dizeres produzidos em outras FDs, cujos sentidos são deslocados, dialogam, transformando-se, reelaborando-se, fazendo com que todos os trajetos de uma região a outra pareçam possíveis.

Outro conceito importante para esta reflexão é apresentado quando Authier- 
-Revuz (1990) trabalha com a noção de heterogeneidade na perspectiva da psicanálise e no nível do enunciado. Com base no dialogismo bakhtiniano, na problemática do discurso como produto do interdiscurso e na teoria do sujeito construído de Lacan, ela distingue duas formas de heterogeneidade: mostrada e constitutiva. A heterogeneidade mostrada apresenta marcas na superfície linguística do texto, sendo, pois, sua manifestação explícita, subdividindo-se em dois aspectos: heterogeneidade marcada e não marcada. As palavras entre aspas e o itálico são algumas formas de heterogeneidade mostrada marcada. $\mathrm{O}$ discurso indireto livre, o pastiche, a ironia são formas não marcadas. A heterogeneidade constitutiva é uma característica inerente à própria linguagem e não necessariamente deve vir marcada no texto para se perceber seus efeitos. Ela é recuperável por meio do interdiscurso, definido por Courtine como:

[...] concernente à existência histórica do enunciado no seio de práticas discursivas [...], capaz de dar origem a atos novos, no sentido de que toda a produção discursiva acontece numa conjuntura dada e coloca em movimento formulações anteriores já enunciadas (1981, p. 51, tradução nossa).

Assim, todo dito é um já dito em outro lugar, que atua de forma decisiva no processo de memória/esquecimento, responsáveis pela ativação de determinadas representações, culturalmente construídas, arquivadas em uma memória discursiva, cultural, socio-histórica, responsável pela produção e interpretação dos efeitos de sentidos produzidos nos diversos enunciados. Conforme Pêcheux, a memória discursiva é tida como:

Aquilo que, em face de um texto que surge como acontecimento a ler vem restabelecer os 'implícitos' (quer dizer, mais tecnicamente, os pré-construídos, elementos citados e relatados, discursos-tranversos, etc) de que sua própria leitura necessita: a condição do legível em relação ao próprio legível (1999, p. 54).

É, pois, na interface entre o real da língua e o real da história, e trabalhando-se com a hipótese da interdiscursividade intrínseca a todo ato de linguagem, que esse jogo de memória e esquecimento se consubstancia, é no ponto em que se constituem o sujeito e o discurso que procedemos a análise da canção Artigo 26, de Ednardo.

\section{"Oropa, França e Ceará": o Artigo 26 na teia do interdiscurso}

Ao se analisar a letra da canção Artigo 26, de Ednardo, podemos verificar como os sentidos são constituídos com base em uma memória discursiva, em dizeres oriundos de outras formações discursivas. Assim, esse manifesto poético em defesa da educação, da cultura e da própria poesia como "pão do espírito" é atravessado de forma constitutiva por pelo menos três regiões do saber/dizer/ poder, fazendo-as dialogar, ressignificando-as, quais sejam: 
a) O discurso da Revolução Francesa - A mobilização dessa região do dizer inicia pelo título da canção. $\mathrm{O}$ artigo 26 refere-se à Declaração Universal dos Direitos do Homem, concebida no processo da Revolução Francesa, a principal revolução burguesa da Europa, que destituiu do poder a monarquia absolutista $(\mathrm{O}$ Ancien Régime) da França e alterou a composição social e política do poder nesse país, influenciando o mundo inteiro com os ideais republicanos e iluministas. O lema da revolução era "Egalité, fraternité e liberté", "Igualité, fraternité e liberté", de acordo com Ednardo (2005a). Uma das conquistas da Revolução Francesa foi o ensino público e gratuito universal, configurada no artigo 26 da referida declaração:

1. Toda a pessoa tem direito à educação. A educação deve ser gratuita, pelo menos a correspondente ao ensino elementar fundamental. $\mathrm{O}$ ensino elementar é obrigatório. O ensino técnico e profissional deve ser generalizado; o acesso aos estudos superiores deve estar aberto a todos em plena igualdade, em função do seu mérito.

2. A educação deve visar à plena expansão da personalidade humana e ao reforço dos direitos do homem e das liberdades fundamentais e deve favorecer a compreensão, a tolerância e a amizade entre todas as nações e todos os grupos raciais ou religiosos, bem como o desenvolvimento das atividades das Nações Unidas para a manutenção da paz.

3 . Aos pais pertence a prioridade do direito de escolher o gênero de educação a dar aos filhos. ${ }^{3}$

Segundo Foucault (1997), analisar um discurso é analisar as condições de possibilidade da sua realização, em síntese, é analisar o motivo pelo qual o enunciado apareceu assim e não de outro jeito. Assim, a presença da língua francesa no texto não ocorre por acaso. É uma marca de heterogeneidade mostrada, marcada na superfície linguística. Constitui-se, pois, como um dos elementos fundamentais no processo de significação, trazendo para a cena enunciativa um dos principais elementos da cultura de um povo que é a sua língua.

Se o texto se utilizasse de outra língua estrangeira na sua superfície, os "efeitos de sentido" seriam outros. A significação do texto depende da mobilização do universo de referências do movimento revolucionário francês, o que é realizado pela utilização de estrangeirismos adaptados. A música, portanto, faz falar a língua francesa para ativar um conjunto de enunciados produzidos nessa região do dizer: a França, a Revolução Francesa.

Essa entrada da língua francesa no texto, no entanto, não ocorre de forma linear. Ela é ressignificada a partir dos elementos da cultura popular do Ceará. A própria utilização da língua francesa com sotaque brasileiro/cearense aponta para o efeito de pastiche, de brincadeira. Aqui, é um francês subvertido, abrasileirado, que também produz efeitos. É a liberdade linguística produzindo efeitos de independência, no sentido de tomar aquele discurso como base para dialogar com ele em duas perspectivas: de aceitação/atualização e de crítica satírica por meio do pastiche. 
O pastiche é um recurso interdiscursivo/intertextual que evidencia a condição interdiscursiva do texto. É uma espécie de hipertexto, visto que se relaciona dialogicamente com outro, o hipotexto, estabelecendo com o texto primeiro uma relação de imitação e de caráter lúdico. De acordo com Genette (1982, p. 56), "le pastiche est l'imitation en regime ludique dont la fonction domminante est le pur divertissement". ${ }^{4} \mathrm{O}$ autor fala da função de divertimento como dominante, não sendo, portanto, única. Nesse caso, o pastiche não tem apenas a função de divertir, mas também de satirizar, ironizar, questionar e mesmo de afirmar uma língua/identidade/cultura.

O pastiche, de acordo com Authier-Revuz,

[...] preserva o afastamento entre as duas fontes enunciativas. Para que seja reconhecido como tal, seu autor é levado frequentemente a introduzir índices de distanciamento (aumentando os efeitos, por exemplo) (1990, p. 29).

É assim que temos, pois, a língua de Verlaine em uma espécie de "franco-cearês" ou "cearensês". ${ }^{5}$ Comparemos as duas formas da escrita do francês:

\begin{tabular}{l|l} 
Egalité, fraternité & Igualité, fraternité \\
et liberté & e liberté \\
Pas de bourré & Pá de burré \\
Merci beaucoup & Merci bocu \\
Il n’y a pas de quoi & Ne pá de quá
\end{tabular}

Por meio desse recurso, observa-se uma postura antropofágica, ${ }^{7}$ ou seja, o texto utiliza o francês, dialoga com ele e o inverte/subverte, utilizando-se dos elementos da cultura do sujeito enunciador no sentido de afirmá-la, em postura semelhante à proposta do Modernismo brasileiro da década de 1920, que buscava a constituição de uma cultura nacional mediante a deglutição antropofágica da cultura estrangeira, postura semelhante ao "sejamos imperialistas", de Caetano Veloso, na canção Língua, autor também influenciado por essa proposta estética. ${ }^{8}$ A antropofagia é a resistência, é a anticolonização, sintetizada no seguinte trecho do manifesto antropófago: "nunca fomos catequizados, fizemos foi o carnaval" (ANDRADE, 1992, p. 356).

\section{b) O discurso da Padaria Espiritual -} Nessa nova padaria espiritual / nessa nova palavra-de-ordem geral / Você trata do delito de comer / de comer/ onde e quando cometer / coma tudo, tudo o que você puder / arrote e coma você mesmo até / consuma tudo em suma / definitiva e completamente (EDNARDO, 2015b).

Outra formação discursiva, cuja presença é fortemente ativada no texto, é o discurso literário apresentado pela composição padaria espiritual, ela própria atravessada pelos ideais da Revolução Francesa no tocante a vários aspectos, como o anticlericalismo e o direito à educação. Um dos recursos mais marcantes do texto é o jogo com a polissemia da palavra pão. 
Olha o padeiro entregando o pão

De casa em casa entregando o pão [...]

(EDNARDO, 2015b).

O pão, além do sentido literal do mesmo campo semântico de padeiro, tem também o sentido deslocado da formação discursiva padaria espiritual. $O$ Pão era o título do jornal dos padeiros. De acordo com Moacir Jurema, nome de guerra de Antônio Salles:

[...] devemos confessar aqui que essa folha (O Pão) era menos o vehiculo litterário da Padaria do que uma válvula para a pilhéria petulante que se fazia lá dentro (1893 apud AZEVEDO, 1996, p. 108).

Outra referência à Padaria Espiritual é o verso:

Você queria mesmo é ser um sanhaçu

Fazendo fiu e voando pelo azul

(EDNARDO, 2015a).

O termo sanhaçu funciona aqui como uma metáfora da liberdade, com base em outro postulado dos padeiros, que é a defesa da fauna e flora nacionais, ${ }^{9}$ visto que o sanhaçu é um pássaro brasileiro. Outra leitura possível é a referência a Aurélio Sanhaçu - pseudônimo ${ }^{10}$ de Antônio de Castro -, um dos integrantes da padaria.

A Padaria Espiritual foi um movimento literário nascido na capital cearense, em fins do século XX, mais precisamente com os poetas Lopes Filho e Lívio Barreto, que apresentava características simbolistas, mantendo, segundo Azevedo (1996), relações com o simbolismo português. Segundo Antônio Sales: "Foi no Java, ${ }^{11}$ com a collaboração material de
Mané Côco, que nascia a Padaria Espiritual" (1893 apud AZEVEDO, 1996, p. 59).

A padaria era uma "sociedade de rapazes de Letras e Artes" cujo fim era "fornecer pão do espírito aos sócios em particular e aos povos em geral" (AZEVEDO, 1996, p. 59). A sede funcionou em três prédios da Rua Formosa, referência presente no texto:

\section{Rua Formosa, moça bela a passear \\ Palmeira verde e uma lua a pratear \\ E um olho vivo vivo a procurar. \\ Mais uma ideia pro padeiro amassar \\ (EDNARDO, 2015a).}

O olho vivo era "O olho da providência”. Os padeiros assim denominavam "o investigador das cousas e das gentes” (AZEVEDO, 1996, p. 59), um deles encarregava-se de pesquisas, de conversas com as pessoas do povo, o que serviria de base para a geração de ideias que seriam "amassadas" pelos demais (amassadores) e transformadas em poesia, causos, pilhérias e qualquer outra "arte do espírito".

Dessa forma, atuando nesse domínio de memória, o sujeito enunciador do texto atualiza o discurso da Padaria Espiritual, ressignificando-o. Insere-se nessa teia discursiva uma perspectiva de assunção desses valores, como se fosse ele um novo padeiro. Para demonstrar esse aspecto, recorremos a artigos do Programa de Instalação da Padaria que tratam da educação infantil: 
XXXII: A padaria representará ao governo do Estado contra o actual horário da Bibliotheca Publica e indicará um outro mais consante às necessidades dos famintos de idéas.

XXIII: Nomear-se-ão comissões para apresentarem relatórios sobre os estabelecimentos de instrução pública e particular da Capital, relatórios que serão publicados.

XXXIX: A padaria desejaria muito crear aulas nocturnas para a infância desvalida, mas como não tem tempo para isso, trabalhará por obrigatória a instrução pública primária (AZEVEDO, 1996, p. 63).

\section{c) O discurso da cultura popular: quadrilha e parlendas -}

Anavantu, anavatu, anarriê

Sabe-se que a quadrilha junina é de origem inglesa, nascida por volta dos séculos XIII e XIV. Durante a Guerra dos Cem Anos, entre França e Inglaterra, a country dance afrancesou-se, virou contredance, uma dança em que os pares executam a coreografia, frente a frente, vis-a-vis. Em dois séculos, essa dança perdeu as características rurais para ganhar os salões da nobreza no século XVIII em toda a Europa, inclusive em Portugal. No Brasil, chegou com os colonizadores, seguindo a terminologia da Espanha e da Itália. Aqui chegando, foi adaptada à realidade local, passando a ser dançada no mês de junho em louvor a São Pedro, a São João e a Santo Antônio, como agradecimento pela colheita. Manteve, no entanto, algumas palavras em francês, mas um francês abrasileirado, como "anavantu", uma adaptação de en avant, avançar, ir adiante, que, na quadrilha, significa ir adiante balançando os braços, e o "anarriê", que significa "voltar aos seus lugares".

Sobre a parlenda, assim define $\mathrm{Bu}$ arque de Holanda: "rimas infantis, em versos de cinco ou seis sílabas, para divertir, ajudar a memorizar ou escolher quem fará tal ou qual brinquedo" ([1986], p. 1038). Exemplos são: hoje é domingo pede cachimbo (ou "do pé do cachimbo", como diz a maioria das pessoas, confundindo os termos por causa da proximidade fonética); um dois, feijão com arroz, três quatro, feijão no prato, etc.; a história da galinha pedrês, parlenda popular do Ceará: "Sabe a história da galinha pedrês? Não. É aquela que deu um 'peido' para nós três".

Assim, por intermédio desses dois elementos oriundos da cultura popular, esses sentidos originais são ressignificados, transformando-se em uma crítica de fina ironia ao discurso dominante excludente no tocante à educação, que teve sua origem na Revolução Francesa.

É sabido que os grupos que conquistaram o poder e destituíram o Ancien Régime não eram homogêneos. Ao contrário, eram bastante heteróclitos, com interesses distintos. É emblemática, por exemplo, a polêmica entre La Chalotais, um pedagogo que lutava para tornar o ensino uma atividade exclusivamente secular. No entanto, ele não desejava estendê-lo a todo o povo. Ensino estatal sim, mas apenas para as classes financeiramente favorecidas, chegando até a condenar os frères ignorantins, integrantes do baixo clero francês que 
ensinavam os rudimentos do alfabeto aos trabalhadores e aos pobres em geral. Segundo ele, ensinar as letras aos operários e camponeses seria desviá-los das tarefas que a natureza e a ordem social tinham determinado para eles. Foi o que bastou para que ninguém menos do que Voltaire, um elitista assumido, congratulasse o pedagogo, pois, para o grande escritor, as luzes não eram para alfaiates e bodegueiros, mas, sim, um apanágio da aristocracia pensante. Também o cura de Lisieux, o padre Réguis, em seus sermões, vociferava contra a inutilidade de alfabetizar os trabalhadores. Dizia ele do seu púlpito que saber ler e escrever não os ensinaria a melhor lavrar a terra, não iria lhes melhorar os costumes, nem lhes tirar a malícia, nem os tornaria mais dóceis ao seu pastor, nem mais virtuosos e nem mais cristãos.

Alguns professores jansenistas (dissidência católica), como Jean-Baptiste Crévier, contra-argumentavam, afirmando que foram os Evangelhos escritos para serem lidos, e que a fé seria reforçada por aqueles que tinham o domínio dos princípios cristãos expressos nos livros.

Essa era a grande contradição da Revolução Francesa. Quando a burguesia assumiu o poder, isolou os setores populares das benesses, quando não os enviou diretamente para à guilhotina. A liberté que pregavam era a liberdade de comércio, a fraternité era entre a alta burguesia, bem como a egalité. Em síntese, a burguesia francesa, vitoriosa, agiu com os camponeses e os setores po- bres da população da mesma forma que a história da galinha pedrês da parlenda popular: deu um "peido" para a igualdade, a liberdade e para a fraternidade, o que é ilustrado pelo texto a seguir:

Você já leu o artigo 26 ou sabe a história da [galinha pedrês

E me traduza aquele rock para o português

A ignorância é indigesta pro freguês

(EDNARDO, 2015a).

Tal leitura é autorizada também pela recorrência do anavant e anarriê, ou seja, avançar e retroceder, que, no texto, adquire o tom de crítica irônica ao discurso da Revolução Francesa.

Assim, por meio dos elementos oriundos dessas três regiões do dizer, em um processo de interdiscursividade, emerge a posição do sujeito do(no) discurso, constituído nessa teia que enuncia do conjunto desses lugares sociais. Um sujeito que, alfabetizado, apropria-se dos elementos pertencentes a diversas FDs (história da França) por meio de um dos principais elementos identitários de um país que é sua língua e dos elementos da sua própria cultura para comê-la antropofagicamente, por meio do pastiche, de uma nouvelle langue: uma espécie de "franco-cearês" ou "franco-cearensês", inserindo-se nessa teia discursiva, não de forma assujeitada, colonizada, mas de forma autoral, criativa e crítica, absorvendo o que "bem merece" e "deixando o que é ruim de lado", como diria Gilberto Gil, em sua canção intitulada Louvação. A denúncia vem por meio da metáfora do 
alçapão, armadilha: "quem se arrisca a cair no alçapão?", pois "a ignorância é indigesta pro freguês” (EDNARDO, 2015a).

Dessa forma, apesar do diálogo com a língua francesa, a palavra final, a última palavra vem em português, produzindo um efeito de afirmação dessa língua, dessa cultura:

Anavantu, anavatu
Anarriê
Ne pá de quá
Ne pá de quá
Pá de burrê
Igualité, fraternité e liberté
Merci bocu, merci bocu,
Não há de quê (EDNARDO, 1976).

\section{Considerações finais}

Tendo em vista que o contato de línguas, independentemente do ângulo que se observe, mobiliza sempre questões identitárias, por meio da análise da letra da canção Artigo 26, do cantor e compositor cearense Ednardo, demonstramos os efeitos de sentido provocados pelo contato da língua portuguesa (com sotaque cearense) e a língua francesa, cujo fio do discurso (intradiscurso) constitui-se com base no entrecruzamento deste com outras formações discursivas: o discurso da história (Revolução Francesa), o discurso literário da Padaria Espiritual, e com alguns elementos da cultura popular do Nordeste, como a quadrilha junina e as parlendas populares.

Em nenhum momento do dispositivo de análise, considerou-se o sujeito empírico, o compositor, mas, antes, a sua função-autoria, uma das posições que o sujeito pode desempenhar no discurso e cujo instituto não existe $a$ priori, de acordo com Michel Foucault, ele é construído/ constituído no e pelo discurso.

Desenredando, pois, o fio do discurso, encontramos um sujeito que enuncia de um lugar social brasileiro/cearense, por meio dos elementos concernentes ao seu espaço enunciativo, mas que dialoga com o discurso do outro, em uma perspectiva antropofágica, de deglutir, digerir esse outro, não de forma passiva, receptiva, mas ressignificando-o, por meio do pastiche, do jogo de palavras, no contato das línguas, como forma de construção/ constituição/afirmação da sua própria cultura/língua/identidade.

Outro aspecto importante a enfatizar é que a análise de um texto, do ponto de vista do discurso, não é um exercício de obviedades, conforme afirmam alguns críticos dessa teoria. Considerando, também, a não obviedade dos lugares sociais dos sujeitos discursivos, observamos que os sentidos não são transparentes. Não é possível encontrar uma essência de sentido sacudindo o texto ou analisando simplesmente o seu conteúdo, pois as palavras mudam de sentido quando passam de uma formação discursiva a outra. É necessário desenredar a teia tênue de entrecruzamentos, cisões, rupturas, diálogos que se emaranham na superfície do texto, e que são o resultado do batimento tenso entre o real da língua e o real da história, labirinto movediço e fascinante no qual é possível encontrar um elo entre o enunciador do texto, a Padaria 
Espiritual, a Revolução Francesa e as parlendas e tradições populares brasileiras por meio desse frutífero exercício do roçar de línguas.

\section{Ednardo's anthropophagic bakery: an analysis on the discourse of the song Artigo 26}

\section{Abstract}

This paper proposes to analyze of the effects of meaning produced by the contact between the Portuguese and the French language in the lyrics of the song Artigo 26 by the composer Ednardo, For this analysis, we mobilize the theoretical and methodological framework of the called French Discourse Analysis, in authors as Michel Pêcheux (1995), Michel Foucault (1997, 1992, 1999) and Courtine (1981), showing the mechanisms on which the text promotes dialogue among the three regions of speaking: a) The French Revolution, b) The literary discourse of Spiritual Bakery (Literary Movement in Ceará in the late nineteenth century) and c) The discourse of Brazilian popular culture (June party, playful rhymes), giving new meaning to the elements of these cultures through pastiche, mood and giving rise an anthropophagic speech and a universal subject that states and takes shape also by elements of local culture.

Keywords: Discourse analysis. Ednardo. Artigo 26.

\section{Notas}

1 Trabalho fruto da pesquisa Terra ardendo, pontes e overdrives: discurso, sujeito e identidade em materialidades diversas (2012/2014), desen- volvida pelo Disculti - Grupo de Estudos em Discurso, Cultura e Identidades da Universidade Regional do Cariri, cujo propósito é analisar discursos sobre nacionalidade/regionalidade, com foco principal no Nordeste brasileiro. Os corpora preferenciais da pesquisa são os textos oriundos das práticas culturais dessa região, como canções, literatura de cordel, lapinhas, reizados, bandas cabaçais, dentre outras demonstrações culturais.

2 Dados disponíveis em: <http://www.ednardo. com.br/>. Acesso em: 29 nov. 2015.

3 Declaração Universal dos Direitos do Homem. Disponível em: <www.unicrio.org.br/Textos/ udhr.htm>. Acesso em: 21 jul. 2015.

4 "O pastiche é a imitação de forma lúdica cuja função dominante é o puro divertimento" (Tradução nossa).

5 Ambas as formas são usadas para designar uma possível língua ou dialeto cearense. O Dicionário de Cearês, de Marcus Gadelha (1999), traz essa forma. O jornal $O$ Povo usa a expressão "cearensês" (entre aspas), em matéria sobre o lançamento do primeiro filme em "cearensês" com legendas em "português": Cine Holliúdy, do diretor Halder Gomes. Vide: O Povo Online (2013).

6 Tais efeitos de sentido somente podem ser mais bem captados com a canção executada, pois na sua forma escrita, perde-se o efeito do sotaque cearense pronunciado [mer'si bo'ku].

7 "Só a antropofagia nos une. Socialmente. Economicamente. Filosoficamente [...]. Contra todos os importadores de consciência enlatada [...] Queremos a Revolução Caraíba, maior que a Revolução Francesa. A unificação de todas as revoltas eficazes na direção do homem. Sem nós, a Europa não teria sequer a sua pobre declaração dos direitos do homem [...] Em Piratininga, ano 374 da Deglutição do Bispo Sardinha" (ANDRADE, 1992, p. 356).

8 "Sejamos imperialistas, cadê [...] E deixem os portugais morrerem à mingua, minha pátria é minha língua. Fala Mangueira" (VELOSO, 2008).

9 Artigo XXI - Será julgada indigna de publicidade qualquer peça litteraria em que se fallar de animaes ou planta extranhas à Fauna e á Flora Brazileira, como - cotovia, olmeiro, rouxinol, carvalho, etc. (PROGRAMA DE INSTALLAÇÃO DA PADARIA ESPIRITUAL, 1892 apud AZEVEDO, 1996, p. 62).

10 De acordo com o artigo VI do Programa de Instalação da Padaria Espiritual, todos os padeiros 
terão um nome de guerra, único pelo qual serão tratados e do qual poderão usar no exercício de suas árduas e humanitárias funções (PROGRAMA DE INSTALLAÇÃO DA PADARIA ESPIRITUAL, 1892 apud AZEVEDO, 1996, p. 60).

11 O Java era um quiosque localizado na Praça do Ferreira, no centro de Fortaleza, comandado por Manuel Pereira dos Miqueletti, o Mané Côco.

\section{Referências}

ANDRADE, Oswald de. Manifesto antropofágico. In: TELLES, Gilberto Mendonça. Vanguarda europeia e modernismo brasileiro: apresentação e crítica dos principais manifestos vanguardistas. 12. ed. Petrópolis: Vozes; Brasília: INL, 1992. p. 356.

AUTHIER-REVUZ, J. Heterogeneidades enunciativas. Cadernos de Estudos Linguísticos, Campinas: Unicamp, v. 19, p. 25-42, jul./ dez. 1990.

AZEVEDO, S. A padaria espiritual e o simbolismo no Ceará. Fortaleza: Casa de José de Alencar, 1996.

BUARQUE DE HOLANDA, A. Novo dicionário Aurélio. 15. reimp. São Paulo: Nova Fronteira, [1986].

CARVALHO, Gilmar de. O Ceará do Ednardo. Fortaleza: Expressão, 2013.

COURTINE, J. J. Analyse du discours politique. Paris: Langages, 1981.

DECLARAÇÃO universal dos direitos do homem. Disponível em: <http://://www. unicrio.org.br/Textos/udhr.htm>. Acesso em: 21 jul. 2015.

EDNARDO. Berro. São Paulo: RCA Victor, 1976. Faixa 2. 1 LP.

. Artigo 26. Disponível em: <https:// www.letras.mus.br/ednardo/45608/>. Acesso em: 21 mar. 2015a.
. Padaria Espiritual. Disponível em: <https://www.letras.mus.br/ednardo/385050/>. Acesso em: 21 mar. 2015b.

FOUCAULT, M. Arqueologia do saber. Rio de Janeiro: Forense Universitária, 1997.

As palavras e as coisas: uma arqueologia das ciências humanas. 8. ed. São Paulo: Martins Fontes, 1999.

GADELHA, Marcus. Dicionário de Cearês. Fortaleza: Multigraf, 1999.

GENETTE, Gérard. Palimpsestes. La Littérature au Second Degré. Paris: Seuil, 1982.

GREGOLIN, M. R. V. Foucault e Pêcheux na análise do discurso: diálogos \& duelos. São Carlos: Claraluz, 2004.

O POVO ONLINE. Confira dicionário do "cearensês" usado em Cine Holliúdy. 2013. Disponível em: <http://www.opovo.com.br/ app/divirta-se/2013/08/13/noticiasdivirtase,3110291/confira-dicionario--do-cearenses.shtml>. Acesso em: 30 nov. 2015.

PÊCHEUX, M. Papel da memória. In: ACHARD. P. et al. Papel da memória. Trad. J. H. Nunes. Campinas: Pontes, 1999.

Semântica e discurso: uma crítica à afirmação do óbvio. Trad. Eni Orlandi. Campinas: Pontes, 1995.

Remontons de Foucault à Spinoza. In: MALDIDIER, D. L'inquietude du discours. Paris: Éditions des Cendres, 1990.

VELOSO, Caetano. Língua. 2008. Disponível em: <http://www.letras.com.br/\#!caetano-veloso/lingua>. Acesso em: 7 jul. 2015. 


\section{ANEXO}

Artigo 26

Ednardo

Olha o padeiro entregando o pão

De casa em casa entregando o pão

Menos naquela, aquela, aquela, aquela não

Pois quem se arrisca a cair no alçapão?

Pois quem se arrisca a cair no alçapão?

Anavantu, anavantu, anarriê

Nê pa dê qua, nê pa dê qua, padê burrê

Igualitê, fraternitê e libertê

Merci bocu, merci bocu

Não há de que

Rua Formosa, moça bela a passear

Palmeira verde e uma lua a pratear

Um olho vivo, vivo, vivo a procurar

Mais uma ideia pro padeiro amassar

Mais uma ideia pro padeiro amassar

Anavantu, anavantu, anarriê

Nê pa dê qua, nê pa dê qua, padê burrê

Igualitê, fraternitê e libertê

Merci bocu, merci bocu

Não há de que

Você já leu o artigo 26

Ou sabe a história da galinha pedrês

E me traduza aquele roque para o português

A ignorância é indigesta pro freguês

A ignorância é indigesta pro freguês

Anavantu, anavantu, anarriê

Nê pa dê qua, nê pa dê qua, padê burrê

Igualitê, fraternitê e libertê

Merci bocu, merci bocu

Não há de que
Você queria mesmo, é ser, um sanhaçu

Fazendo fio e voando pelo azul

Mas nesse jogo lhe encaixaram, e é uma

[loucura

Lá vem o padeiro, pão na boca é o que te cura

Lá vem o padeiro, pão na boca é o que te cura

Anavantu, anavantu, anarriê

Nê pa dê qua, nê pa dê qua, padê burrê

Igualitê, fraternitê e libertê

Merci bocu, merci bocu

Fonte: <https://letras.mus.br/ednardo/45608/>. 